Document downloaded from:

http://hdl.handle.net/10251/81703

This paper must be cited as:

Hernández Morejudo, S.; Zanón González, R.; Escolástico Rozalén, S.; Yuste Tirados, I.; Malerod Fjeld, H.; Vestre, PK.; Coors, WG.... (2016). Direct conversion of methane to aromatics in a catalytic co-ionic membrane reactor. Science. 353(6299):563-566. doi:10.1126/science.aag0274.

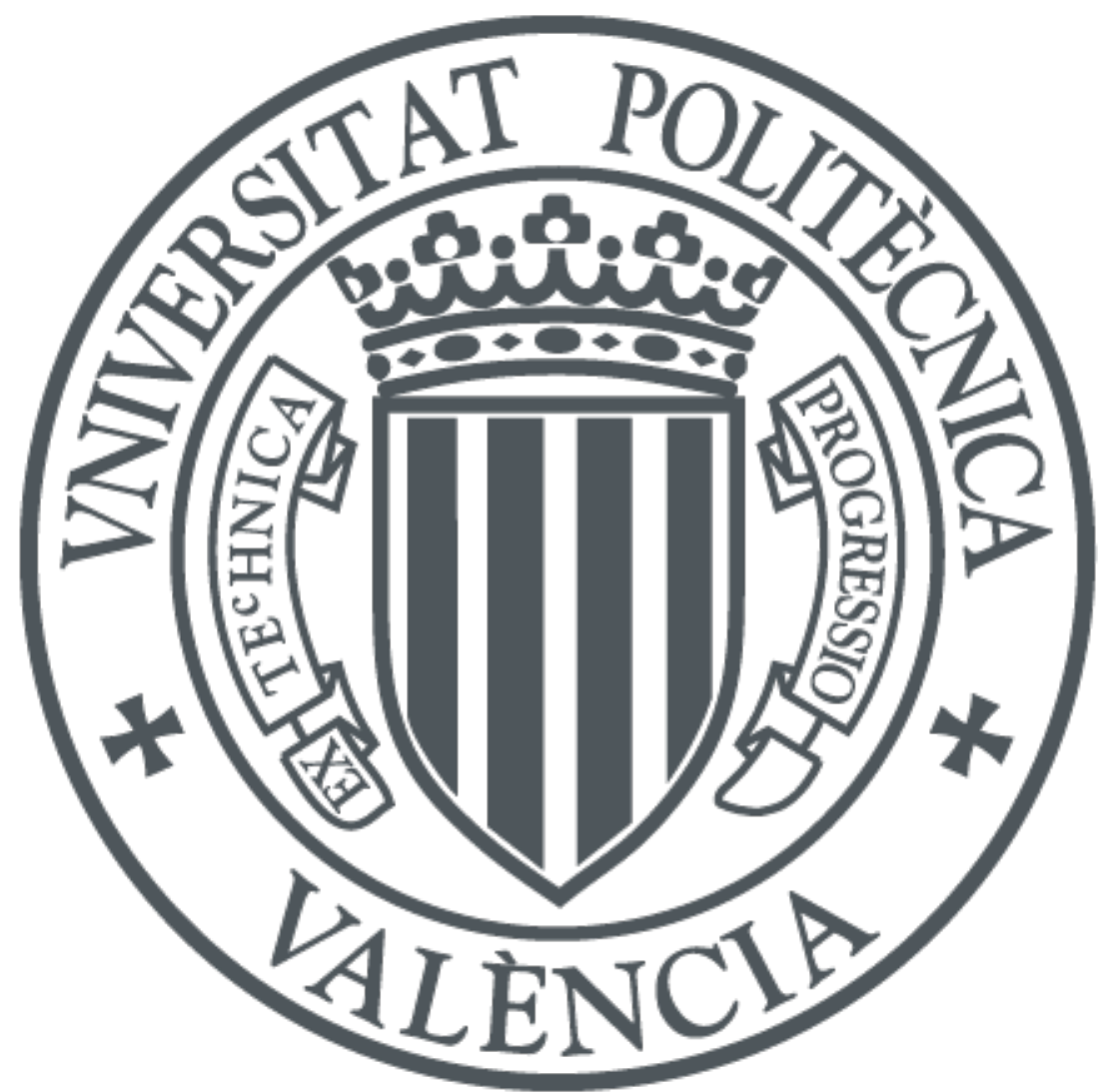

The final publication is available at

http://doi.org/10.1126/science.aag0274

Copyright American Association for the Advancement of Science

Additional Information 


\title{
Direct conversion of methane to aromatics in a catalytic co-ionic membrane reactor
}

\author{
S.H. Morejudo, R. Zanón ${ }^{2}$, S. Escolástico ${ }^{2}$, I. Yuste ${ }^{I}$, H. Malerød-Fjeld ${ }^{I}$, P. K. Vestre ${ }^{I}$, \\ W. G. Coors ${ }^{1}$, A. Martínez ${ }^{2}$, T. Norby ${ }^{3}$, J. M. Serra ${ }^{2^{*}}$, C. Kjølseth ${ }^{1^{*}}$ \\ ${ }^{1}$ Coorstek Membrane Sciences, Forskningsparken, Gaustadalléen 21, NO-0349 Oslo, Norway. \\ ${ }^{2}$ Instituto de Tecnología Química (Universitat Politècnica de València - Consejo Superior de \\ Investigaciones Científicas) Av. de Naranjos s/n, 46022 Valencia, Spain. \\ ${ }^{3}$ Department of Chemistry, University of Oslo, FERMiO, Gaustadalléen 21, NO-0349 Oslo, \\ Norway. \\ *corresponding authors (email): jmserra@itq.upv.es, ckjolseth@coorstek.com
}

\begin{abstract}
:
Non-oxidative methane dehydroaromatization (MDA:6CH$\leftrightarrow \mathrm{CH}_{6} \mathrm{H}_{6}+9 \mathrm{H}_{2}$ ) using shapeselective Mo/zeolite catalysts is a technology to exploit stranded natural gas reserves by direct conversion into transportable liquids. The reaction, however, faces two major issues: the onepass conversion/yield is limited by thermodynamics, and the catalyst deactivates fast due to the kinetically-favored formation of coke. Here we show that integration of an electrochemical $\mathrm{BaZrO}_{3}$-based membrane exhibiting both proton and oxide ion conductivity into an MDA reactor enables high aromatic yields and outstanding catalyst stability. These effects originate from the simultaneous extraction of hydrogen and distributed injection of oxide ions along the reactor length. Further, we demonstrate that the electrochemical co-ionic membrane reactor enables high carbon efficiencies (up to 80\%) significantly improving the techno-economic process viability, and sets the ground for its commercial deployment.
\end{abstract}

One Sentence Summary: The integration of a co-ionic membrane in a MDA reactor remarkably enhances aromatics yield and catalyst lifetime.

\section{Main text:}

Natural gas constitutes a large and relatively clean fraction of the fossil hydrocarbon resources, but high capital cost of multi-stage industrial conversion via syngas leaves much of it stranded. Non-oxidative methane dehydroaromatization (MDA) is a promising catalytic route allowing direct conversion of natural gas into valued petrochemicals such as benzene. The MDA reaction is conventionally run at around $700^{\circ} \mathrm{C}$ in presence of bifunctional catalysts comprising carbided molybdenum nanoclusters dispersed in acidic shape-selective zeolites such as ZSM-5 and MCM-22 (1). The process suffers from two major hurdles that challenge its further development and industrial implementation: The per-pass conversion to aromatics is limited by thermodynamics, and the catalyst activity rapidly drops with time on stream owing to the accumulation of polyaromatic-type coke on the external zeolite surface that impedes the access to internal active sites $(2,3)$. Attempts to overcome thermodynamic limitations by selective removal of the co-product hydrogen from the MDA reactor using, for instance, Pd-type (4) or ceramic $\left(\mathrm{La}_{5.5} \mathrm{~W}_{0.6} \mathrm{Mo}_{0.4} \mathrm{O}_{11.25-\delta}\right)$ (5) membranes were not satisfying due to enhanced coke formation that accelerated catalyst decay. Strategies based on finetuning the zeolite acidity and porosity and co-feeding small amounts of $\mathrm{CO}_{2}, \mathrm{CO}, \mathrm{H}_{2}$, and $\mathrm{H}_{2} \mathrm{O}$ with methane were applied to stabilize the catalyst by restraining coking, but with limited success $(2,6,7)$. Recently, a direct non-oxidative methane conversion path on singleiron sites embedded in a silica matrix $\left(\mathrm{Fe} @ \mathrm{SiO}_{2}\right)$ with almost no coke formation and high stability has been reported (8). This however requires very harsh conditions $\left(950^{\circ} \mathrm{C}\right)$ and produces ethylene (rather than liquids) as the major product with selectivity of ca. $55 \%$. 
We here present a novel approach to circumvent the current limitations of MDA reaction by integrating an ion-conducting membrane in the catalytic reactor. We report an innovative catalytic membrane reactor (CMR) for intensification of the MDA process, resulting in high and prolonged aromatic yields. The CMR is driven by a tailored co-ionic membrane that enables fast and accurate simultaneous control of hydrogen extraction and injection of oxygen species along the catalyst bed (Fig. 1A). The concerted action of both functions leads to unprecedented gains in terms of aromatics yield and catalyst stability, and consequently enabling the MDA technology.

The electrolyte of the membrane is based on acceptor doped $\mathrm{BaZrO}_{3}$ which takes up protons from steam and exhibits high proton $\left(\mathrm{H}^{+}\right)$and minor oxide ion $\left(\mathrm{O}^{2-}\right)$ conductivity at elevated temperatures (9). Applications using its protonic conductivity have shown promising results (10-12), but, as shown here, it is in fact the co-ionic transport property of the material, more specifically the conduction ratio of protons and oxide ions, that allows the successful implementation into the MDA process. The tubular membrane consists of a dense $25 \mu \mathrm{m}$ thick $\mathrm{BaZr}_{0.7} \mathrm{Ce}_{0.2} \mathrm{Y}_{0.1} \mathrm{O}_{3-\delta}$ (BZCY72) electrolyte film on a porous BZCY72-Ni support which also works as the cathode (11). The metallic Ni has sufficient catalytic activity for the hydrogen evolution and reduction of steam (Fig. 1B). A Cu-based anode is applied on the electrolyte film so as to face the catalyst. It activates the electrochemical oxidation of $\mathrm{H}_{2}$ into protons while preventing secondary conversion of hydrocarbons into coke as typically reported for Ni- or Pt-based electrodes (13). As the current density is increased, both hydrogen extraction and oxygen injection increase proportionally, where the amount of oxygen injected is about $0.3 \%$ that of extracted hydrogen (Fig. 1C).

Figure 2 shows results of MDA experiments, comparing our CMR with a fixed bed reactor (FBR) under otherwise similar conditions utilizing 6Mo/MCM-22 as catalyst. The catalyst behaviour in the FBR is fully representative of the state-of-the-art at standard MDA conditions: the aromatics yield initially increases during the induction period, reaches a maximum of ca. $10 \%$, and rapidly falls as the reaction progresses. In contrast, by applying an electrical current to the CMR (ON mode) the aromatics yield continues to increase beyond the induction period and attains a maximum of ca. $12 \%$ after which the catalyst activity starts to decline (Fig. 2A). Worth to note is the almost instant catalytic response (also for conversion, see Fig. S2) to ON-OFF switching as well as to changes in the intensity of the imposed electrical current, which empowers our CMR system with the ability to accurately tune the catalytic performance. Interestingly, the enhancement in conversion/yield observed upon current application occurs while maintaining the characteristic high selectivity to aromatics, particularly to benzene ( $>85 \%$ on a coke-free basis, Fig. $2 \mathrm{~B})$ of the shape-selective $6 \mathrm{Mo} / \mathrm{MCM}-22$ catalyst. Note, however, that operation in the CMR produces some $\mathrm{CO}$, albeit in relatively low selectivity (vide infra). The most striking result in Fig. 2A is, certainly, the excellent stability of the catalyst in the CMR, with an average decay rate about one order of magnitude lower than that observed in the conventional FBR. In consequence, while the aromatics yield lowers to only $\sim 1.5 \%$ in the FBR after $45 \mathrm{~h}$ of reaction, it remains as high as $\sim 9 \%$ in the CMR, translating into a two-fold increase in the cumulative yield (Fig. 2C). The remarkable stability exhibited by the catalyst in the CMR arises from a decreased cokeforming tendency, which becomes more evident at increasing reaction times (Fig. 2C).

Thermodynamic calculations predict that in situ $\mathrm{H}_{2}$ extraction increases methane conversion and shifts selectivity towards heavier aromatics (and ultimately coke) at the cost of benzene and $\mathrm{C}_{2}$ hydrocarbons (Fig. S3), as experimentally proved using $\mathrm{H}_{2}$ permselective membranes $(14,15)$. While thermodynamics thus account for the increase in methane conversion, the high benzene selectivity and improved catalyst stability during the galvanic 
operation in our CMR cannot be anticipated by considering merely effects related to the in situ $\mathrm{H}_{2}$ extraction.

The BZCY72 membrane enables the concomitant transport of oxide ions towards the catalytic reaction medium where they rapidly oxidize the produced $\mathrm{H}_{2}$ to steam at the electrode (16). We therefore investigated the isolated effect of steam on the performance of $6 \mathrm{Mo} / \mathrm{MCM}-22$ catalyst in the FBR by co-feeding $0.25-0.9$ mol\% steam together with methane, corresponding to steam concentrations within the range achieved by the oxygen injection in our CMR. Whereas the observed decrease in both conversion and aromatics selectivity (Fig. S4) is thermodynamically consistent (17), post-reaction characterization of the spent catalysts by TGA and TPO analyses shows that the improved stability achieved in the CMR is ascribed to the inhibition of coke formation by the in situ generated steam (Fig. S5). The steam-promoted coke suppression during MDA has also been reported for an oxygen-permeable membrane reactor (18) and likely occurs by a mechanism involving scavenging of reactive carbon from the catalyst surface via steam reforming (19), which accounts for the observed formation of CO (Fig. 2b). It is worth noticing the superior stability achieved in our CMR as compared to the FBR experiment with an equivalent steam concentration $(0.25 \mathrm{~mol} \%)$. This indicates that the controlled and distributed oxygen injection is more effective in improving the catalyst stability than the continuous external addition of steam. Additionally, the analysis of the XANES spectra at the Mo K-edge and XPS Mo3d spectral signals (Fig. S5-Table S1) did not reveal appreciable changes in Mo speciation during CMR operation with respect to the FBR fed with pure methane. Conversely, a higher average Mo oxidation state is inferred for the catalyst used in the FBR experiment co-fed with 0.9 mol\% steam, which might imply a certain loss of active molybdenum carbide species by reoxidation (19). We highlight that the crystalline structure of the zeolite host remained almost intact upon contact with the in situ generated steam under MDA conditions (Fig. S5). Therefore, the distributed $\mathrm{O}_{2}$ injection allowed by the BZCY72 membrane effectively reduces the coking rate while preserving the structural integrity of the zeolite and active Mo-carbide sites.

A key hypothesis motivating the CMR is that in situ extraction of $\mathrm{H}_{2}$ will shift the equilibrium of the formation of aromatics and this will have major consequences in the process industrialization. In Fig. 3A the experimentally obtained yield of aromatics is plotted as a function of the magnitude of both $\mathrm{H}_{2}$ extracted and $\mathrm{O}_{2}$ injected. High $\mathrm{H}_{2}$ extraction rates ( $>60 \%$ ) with respect to the $\mathrm{H}_{2}$ produced in the MDA reaction can be achieved by using the electrochemical cell reactor. By increasing the magnitude of the imposed co-ionic current, the aromatic yield raises and surpasses the theoretical equilibrium yield (12.3\%) at $\mathrm{H}_{2}$ extraction rates above $50 \%$. As expected from the coke-suppression mechanism operating in the CMR, $\mathrm{CO}$ formation is negligible when no current is imposed and raises parallel to the aromatics yield with increasing co-ionic currents (Fig. 3A). These results unambiguously prove the galvanic-driven solid-state injection of atomic oxygen ions. As a consequence of the oxide ion supply and the resulting reduced coking, the catalyst degradation rate drastically drops by a factor of 6 with respect to the FBR at low extraction rates and then continues decreasing smoother at increasing currents (Fig. 3B).

To assess the practical implications of the described CMR we have performed process simulations using Aspen tools. Fig. 4A schematizes a complete gas-to-liquid process based on our MDA reactor architecture and includes recycling of the reactant methane stream. In this process, the critical parameter for maximizing the per-pass conversion is the hydrogen concentration in the recycle loop. By including a methanation stage, $\mathrm{CO}$ is converted to methane and steam giving a typical $\mathrm{H}_{2}$ concentration of $5 \%$ at the reactor inlet (Fig. S7). Experimental CMR results under recycle operating conditions $\left(5 \% \mathrm{H}_{2}\right.$ co-feed) gives 
aromatics yields ca. $6.5 \%$ with near-zero degradation rate (Fig. 4B). The process performance metrics (Fig. 4C) for different extraction rates (60- 80\%) are compared with (i) a plant based on a conventional MDA reactor, implementing downstream gas fractioning using polymeric membranes (FBR-PolyM) (20); and (ii) a plant based on a CMR employing Pd-membranes (Pd-CMR) (4). Carbon efficiency is superior for our CMR system, improving steeply with increasing extraction rates. At rates above $80 \%$, the carbon efficiency achieved is similar to that exhibited by large and optimized Fischer-Tropsch (FT) plants. The difference between both processes relies on plant size and complexity. While traditional FT process requires multiple steps including syngas production, the MDA co-ionic CMR produces aromatics directly. This feature allows for modularity and flexibility to adapt to the size of the natural gas field in contrast to FT plants that become uneconomic at small/medium scale (1 to 10 metric tons hour $^{-1}$ ).

A

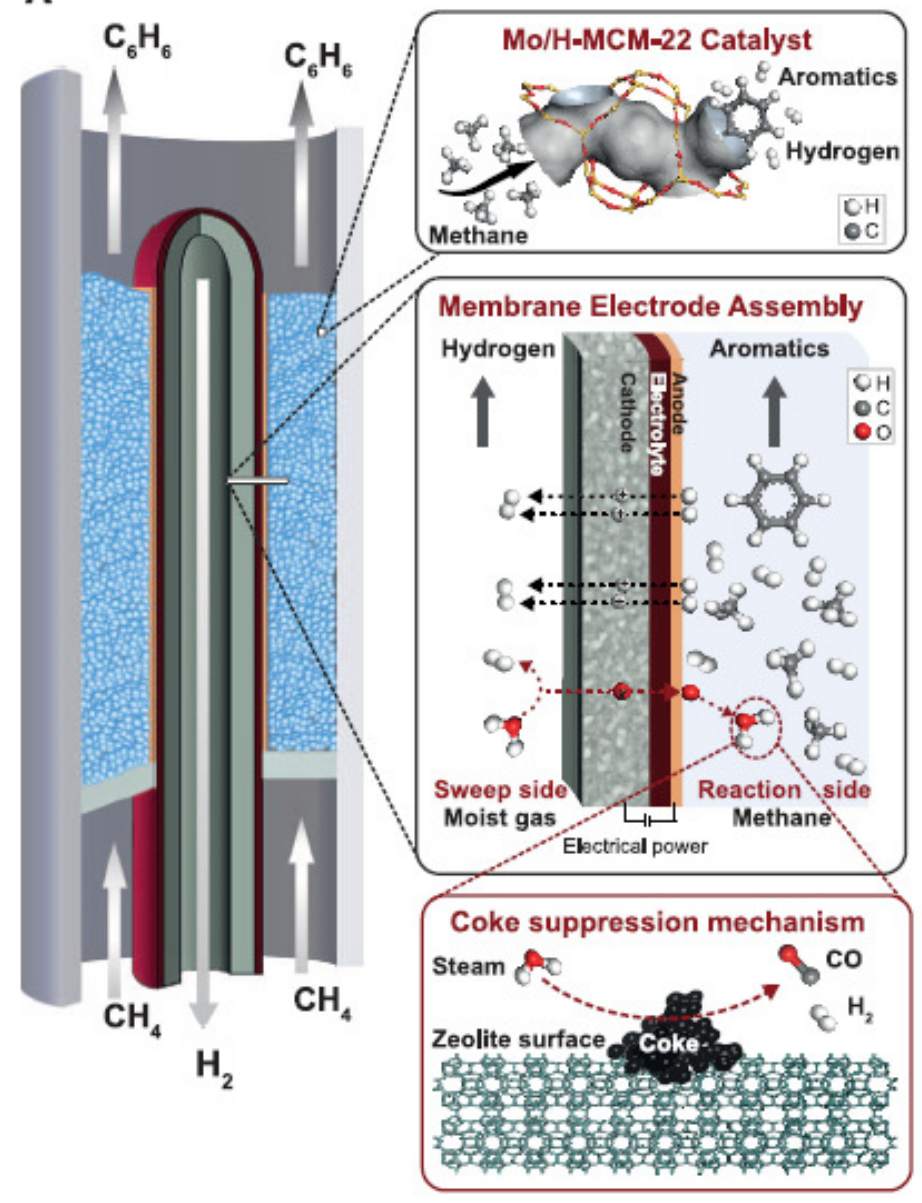

B

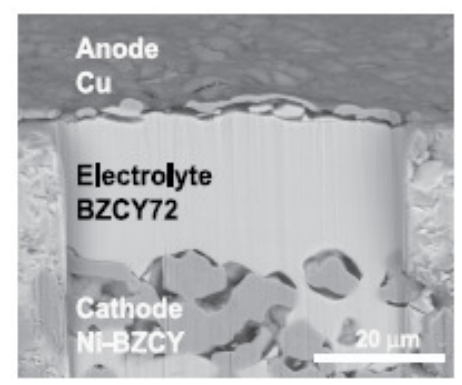

C

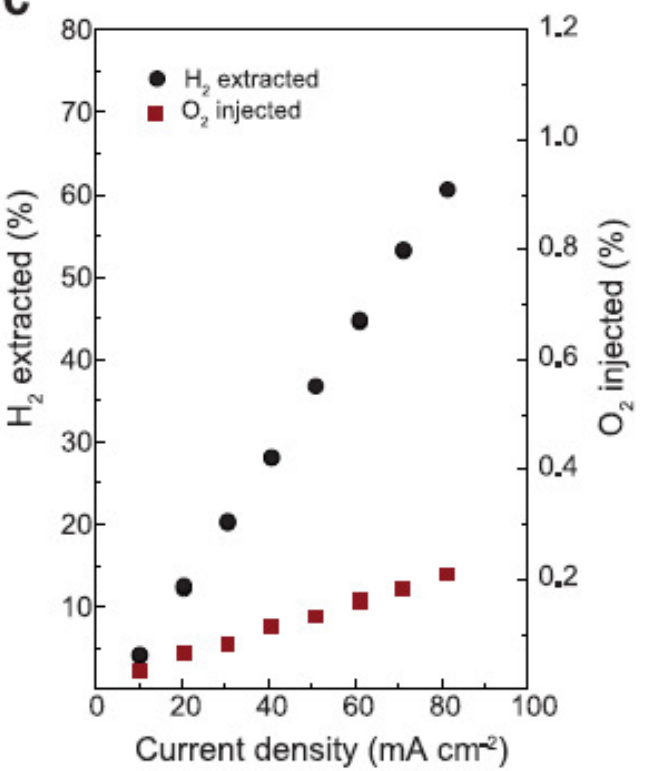

Fig. 1. Current controlled co-ionic membrane reactor. (A) Methane is converted to benzene and hydrogen over $\mathrm{Mo} /$ zeolite. Hydrogen is transported as protons to the sweep side. Oxide ions are transported to the reaction mediumto react with $\mathrm{H}_{2}$ and form steam as intermediate before to react with coke to form $\mathrm{CO}$ and $\mathrm{H}_{2}$. (B) SEM images of themembrane electrode assembly (FIB section). Cathode porosity formed upon reduction of $\mathrm{NiO}$ can be observed beneath the dense electrolyte. (C) $\mathrm{H}_{2}$ extracted and $\mathrm{O}_{2}$ injected (\%) versus current density at $700^{\circ} \mathrm{C}$.Cathode is swept with $\mathrm{H}_{2} / \mathrm{CH}_{4}(10 / 90)$ and anode with $\mathrm{H}_{2} \mathrm{O} / \mathrm{H}_{2} / \mathrm{Ar}(3 / 5 / 92)$. 

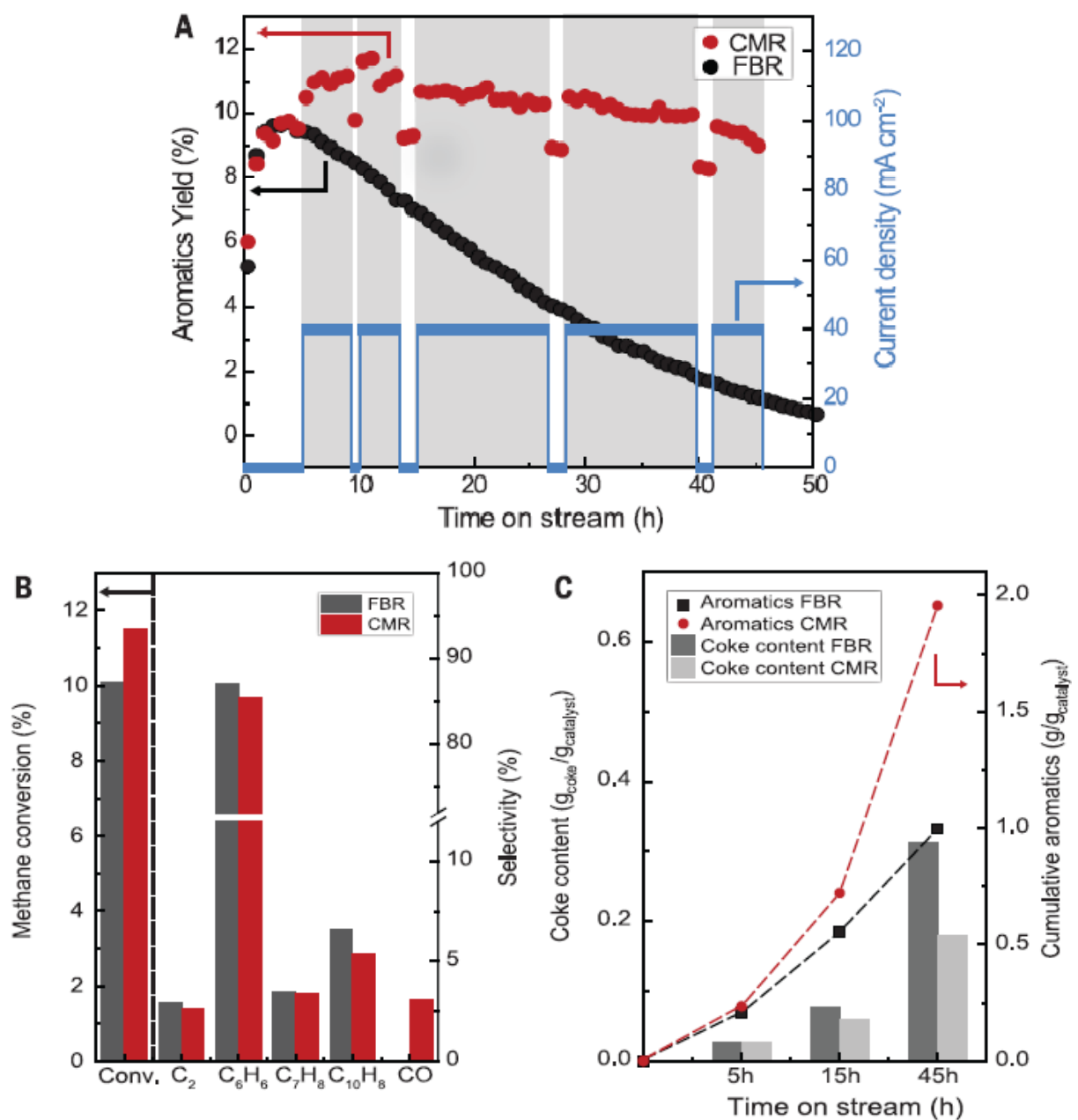

Fig. 2. FBR and co-ionic CMR performance in MDA over Mo/MCM-22 $\left(710^{\circ} \mathrm{C}, 1500 \mathrm{~mL} \mathrm{~g}{ }^{-1}\right.$ $\mathrm{h}^{-1}, 1$ bar and current density of $40 \mathrm{~mA} / \mathrm{cm}^{2}$ ). (A), Aromatics (benzene, toluene and naphthalene) yield versus time on stream. Greyed areas indicate when hydrogen is extracted. (B) Methane conversion and selectivity to main products after 5 and $9 \mathrm{~h}$ on stream. (C), Coke deposition in Mo/MCM-22 catalyst and cumulative aromatics production in gram per gram of catalyst.
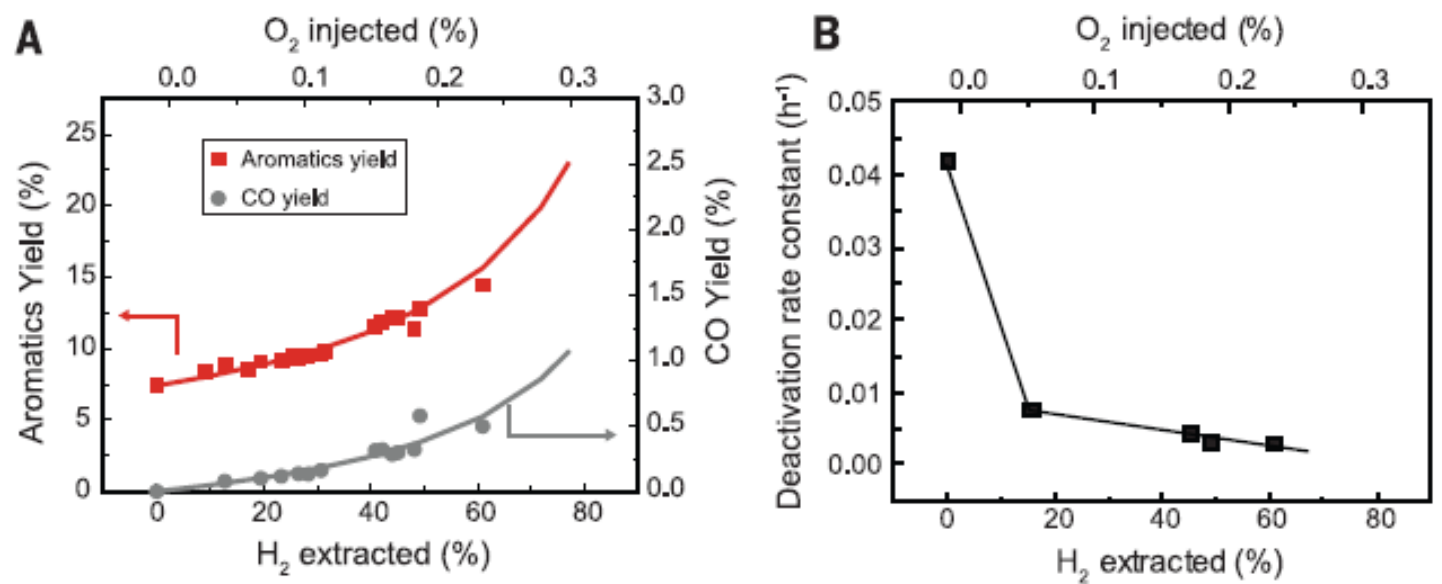

Fig. 3. Effect of co-ionic membrane reactor.(A)Aromatics (benzene, toluene and naphthalene) and $\mathrm{CO}$ yield as a function of $\mathrm{H}_{2}$ extracted and $\mathrm{O}_{2}$ injected at $700{ }^{\circ} \mathrm{C}$ and 1 bar. (B) Deactivation rate constant, assuming first-order catalyst decay, as a function of $\mathrm{H}_{2}$ extracted and $\mathrm{O}_{2}$ injected to the feed side. 

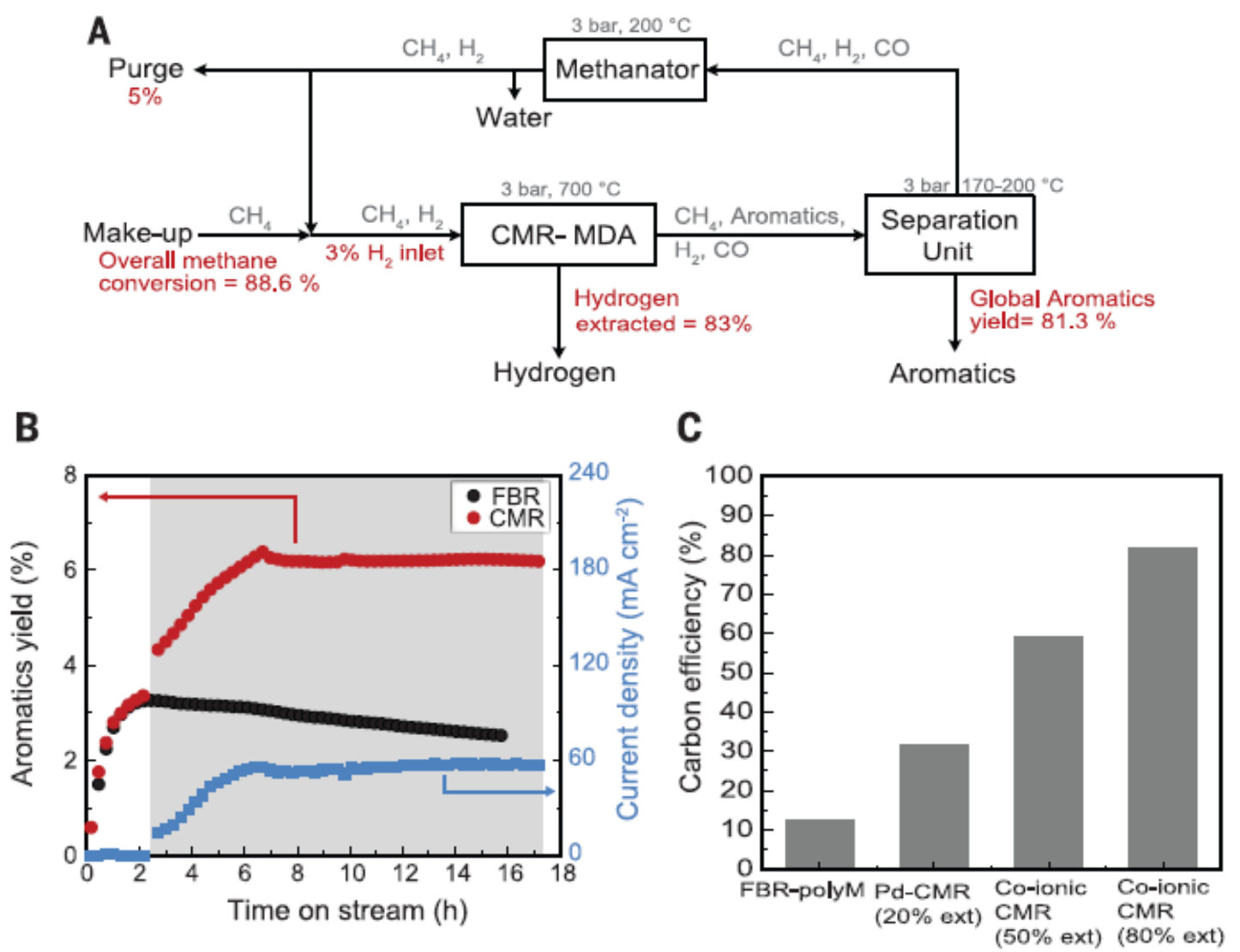

Fig.4. Synloop process for MDA using co-ionic CMR. (A) Flow diagram of process using coionic CMR. (B) Aromatics (benzene, toluene and naphthalene) yield versus time on stream at $700{ }^{\circ} \mathrm{C}, 3000 \mathrm{~mL} \mathrm{~g}^{-1} \mathrm{~h}^{-1}, 3$ bar and $5 \% \mathrm{H}_{2}$ co-feeding. Greyed area indicates when hydrogen is extracted. (C) Carbon efficiency of a synloop process using co-ionic CMR (700 ${ }^{\circ} \mathrm{C}, 3$ bar) for two different $\mathrm{H}_{2}$ extraction: 50 and $80 \%$ compared with plants based on Pd-membrane CMR (4) and FBR with external $\mathrm{H}_{2}$ removal (polymer membrane) (20).

\section{References:}

1. J. Gao et al., Identification of molybdenum oxide nanostructures on zeolites for natural gas conversion. Science348, 686-690 (2015).

2. Y. Xu, X. Bao, L. Lin, Direct conversion of methane under nonoxidative conditions. Journal of Catalysis216, 386-395 (2003).

3. C. H. L. Tempelman, E. J. M. Hensen, On the deactivation of Mo/HZSM-5 in the methane dehydroaromatization reaction. Applied Catalysis B-Environmental176, 731739 (2015).

4. S. Natesakhawat et al., Improved benzene production from methane dehydroaromatization over Mo/HZSM-5 catalysts via hydrogen-permselective palladium membrane reactors. Catalysis Science \& Technology5, 5023-5036 (2015).

5. J. Xue et al., Gas to Liquids: Natural Gas Conversion to Aromatic Fuels and Chemicals in a Hydrogen-Permeable Ceramic Hollow Fiber Membrane Reactor. Acs Catalysis6, 2448-2451 (2016).

6. J. J. Spivey, G. Hutchings, Catalytic aromatization of methane. Chemical Society Reviews43, 792-803 (2014).

7. Z. R. Ismagilov, E. V. Matus, L. T. Tsikoza, Direct conversion of methane on Mo/ZSM-5 catalysts to produce benzene and hydrogen: Achievements and perspectives. Energy and Environmental Science1, 526-541 (2008). 
8. X. Guo et al., Direct, Nonoxidative Conversion of Methane to Ethylene, Aromatics, and Hydrogen. Science344, 616-619 (2014).

9. K. D. Kreuer, Aspects of the formation and mobility of protonic charge carriers and the stability of perovskite-type oxides. Solid State Ionics125, 285-302 (1999).

10. C. Duan et al., Readily processed protonic ceramic fuel cells with high performance at low temperatures. Science349, 1321-1326 (2015).

11. V. Kyriakou et al., Methane steam reforming at low temperatures in a $\mathrm{BaZr} 0.7 \mathrm{Ce} 0.2 \mathrm{Y} 0.1 \mathrm{O} 2.9$ proton conducting membrane reactor. Applied Catalysis $B$ Environmental186, 1-9 (2016).

12. E. Vasileiou et al., Reaction Rate Enhancement During the Electrocatalytic Synthesis of Ammonia in a BaZr0.7Ce0.2Y0.1O2.9 Solid Electrolyte Cell. Topics in Catalysis58, 1193-1201 (2015).

13. Y. Chen et al., Direct-methane solid oxide fuel cells with hierarchically porous Nibased anode deposited with nanocatalyst layer. Nano Energy10, 1-9 (2014).

14. A. K. Kinage, R. Ohnishi, M. Ichikawa, Marked enhancement of the methane dehydrocondensation toward benzene using effective Pd catalytic membrane reactor with Mo/ZSM-5. Catalysis Letters88, 199-202 (2003).

15. Z. Liu, L. Li, E. Iglesia, Catalytic pyrolysis of methane on Mo/H-ZSM5 with continuous hydrogen removal by permeation through dense oxide films. Catalysis Letters82, 175-180 (2002).

16. A. Atkinson et al., Advanced anodes for high-temperature fuel cells. Nat. Mater.3, 1727 (2004).

17. P. Moghimpour Bijani, M. Sohrabi, S. Sahebdelfar, Thermodynamic analysis of nonoxidative dehydroaromatization of methane. Chemical Engineering \& Technology35, 1825-1832 (2012).

18. Z. W. Cao et al., Natural gas to fuels and chemicals: Improved methane aromatization in an oxygen-permeable membrane reactor. Angew. Chem.-Int. Edit.52, 13794-13797 (2013).

19. S. Liu, R. Ohnishi, M. Ichikawa, Promotional role of water added to methane feed on catalytic performance in the methane dehydroaromatization reaction on Mo/HZSM-5 catalyst. Journal of Catalysis220, 57-65 (2003).

20. Y. Shudo, T. Ohkubo, Y. Hideshima, T. Akiyama, Exergy analysis of the demonstration plant for co-production of hydrogen and benzene from biogas. International Journal of Hydrogen Energy34, 4500-4508 (2009).

21. W. G. Coors, Co-Ionic Conduction in Protonic Ceramics of the Solid Solution, $\mathrm{BaCe}_{(\mathrm{x})} \mathrm{Zr}_{(\mathrm{y}-\mathrm{x})} \mathrm{Y}_{(1-\mathrm{y})} \mathrm{O}_{3-\delta}$. Part I: Fabrication and microstructure. Advances in Ceramics Synthesis and Characterization, Processing and Specific Applications, DOI: 10.5772/30672 (2011).

22. S. Ricote, N. Bonanos, H. J. Wang, R. Haugsrud, Conductivity, transport number measurements and hydration thermodynamics of $\mathrm{BaCe}_{0.2} \mathrm{Zr}_{0.7} \mathrm{Y}_{(0.1-\xi)} \mathrm{Ni}_{\xi} \mathrm{O}_{(3-\delta)}$. Solid State Ionics 185, 11-17 (2011).

23. A. Corma, C. Corell, J. Pérez-Pariente, Synthesis and characterization of the MCM-22 zeolite. Zeolites15, 2-8 (1995).

24. A. K. E. Andersson, S. M. Selbach, C. S. Knee, T. Grande, Chemical Expansion Due to Hydration of Proton-Conducting Perovskite Oxide Ceramics. Journal of the American Ceramic Society97, 2654-2661 (2014). 


\section{Acknowledgments:}

This work has been supported by the Research Council of Norway (195912, 210418, 210765 and 219194 grants) and Spanish Government (SEV-2012-0267 grant). The ALBA Synchrotron Light Laboratory is thanked for the provision of beam time. C.K. and P.K.V. have applied for a patent based on this work (PCT/EP2014/071697). Experimental data are available online at ftp://itqrepositorio.itq.upv.es/pub/.

\section{Supplementary materials:}

www.sciencemag.org/content/353/6299/563/supp1/DC1

Materials and Methods

Figs. S1 to S9

Tables S1 and S2

References (24-27) 